\title{
The policy debate on sustainability: issues and strategy
}

\author{
Petar Sabev Varbanov ${ }^{1}$
}

Published online: 4 September 2019

(c) Springer-Verlag GmbH Germany, part of Springer Nature 2019

It has been argued in a previous Editorial (Varbanov, P.S., Sikdar, S. \& Lee, C.T., Contributing to sustainability: addressing the core problems, Clean Techn Environ Policy (2018) 20: 1121. https://doi.org/10.1007/s10098-018-15818 ) that the core problems before attaining a sustainable development trajectory lie in the considerable energy losses to the ambient over the complete energy supply chainsresource extraction, conversion, distribution and use. While all human activities can be mapped to energy demand and use, the energy-related environmental impacts are also significant. Therefore, the impacts left by energy supply need a careful approach.

What are the major environmental and health issues of today? There are varying assessments, which partially overlap:

- Deutche Welle (https://www.dw.com/en/five-of-theworlds-biggest-environmental-problems/a-35915705) and the popular web platform "Inhabitat" (https://inhab itat.com/top-6-environmental-issues-for-earth-day-andwhat-you-can-do-to-solve-them/) put emphasis on Climate Change, pollution of natural air and water storages, deforestation, water scarcity, biodiversity loss, soil problems and overpopulation.

- The World Health Organization (WHO, https://www. who.int/phe/health_topics/en/) takes a different angle, related to human health, discussing the health problems of various key groups in the Earth's population-children's health, occupational health, relating them to immediate causes such as electromagnetic fields, ionising radiation, pollution and safety.

- The Brookings Institution (https://www.brookings.edu/ research/environmental-policy-the-next-generation/) has compiled a strategic analysis, pointing out that while

Petar Sabev Varbanov

varbanov.petar@ppke.hu

1 Centre for Process Systems Engineering and Sustainability, Pázmány Péter Catholic University, Budapest, Szentkirályi utca 28,1088 , Hungary the first three decades of environmental protection have achieved good successes-such as limiting pollution from cars and constraining within certain limits pollution of water by industry in some regions, the remaining challenges in environmental and human health protection remain enormous. The analysis reasons that the new generation challenges lie in the distributed nature and the multitude of the sources of environmental threats, citing fertiliser runoff and water eutrophication issues.

Those are not all global and imminent threats to the environment and health. Of similar magnitude are microplastics pollution (de Souza Machado AA, Kloas W, Zarfl C, et al. (2018) Microplastics as an emerging threat to terrestrial ecosystems. Global Change Biology 24:1405-1416. https ://doi.org/10.1111/gcb.14020) as well as dead zones in the World Ocean (https://www.theguardian.com/environmen t/2018/jan/04/oceans-suffocating-dead-zones-oxygen-starv ed) which start from the coastal areas of the developed regions and keep spreading into the deep seas. Adding to that are the severe problems with particulates all over the developed cities in the World, coming from transport and industrial sources.

The list of problems can be extended for tens of pages more, and all those issues are important on their own. However, an alarming buzz keeps appearing in my mind, popping a question. How much are these issues related, transforming the multitude of problems into a giant integrated web, a reincarnation of the proverbial Hydra? This is an important question to be asked by researchers and policymakers.

The understanding of the simultaneous multitude of environmental and health issues prompts the development of similarly comprehensive measures for counteracting the deterioration trends, bringing human society on a sustainable path. In this respect, there is one bright example of combining several problems for deriving a collective solution to all of them. This example comes from a project, named Sea Harmony (http://sea-harmony.com/en/), by a group of marine biology experts, who have developed artificial reef facilities, based on mussels and applying an ecosystem 
recreation approach. The vertical reef-based facilities for open-sea mussel farming create integrated micro-ecosystems, taking as food the excessive nutrients in the seawater. The platform website claims that this technology recovers the health of damaged coastal areas, by restoring their food chain-phytoplankton, mussels, shrimp, fish and mammals, in this way also providing the opportunity for food production.

While the technology has been already tested at pilot scale, its global environmental impacts need to be further assessed. While still work in progress, this technology development effort provides a valuable lesson: the measures for acting upon environmental issues can also be delivered in a simultaneous multitude of effects, building a synergy.

Although not directly related, the approach taken by Sea Harmony reminds another remarkable method-Process
Integration (Linnhoff B, Townsend DW, Boland D, et al. (1982) A user guide on process integration for the efficient use of energy, 2nd Ed. Rugby, UK), which started by developing a unified understanding of process heating, cooling, emissions and capital costs, finally delivering a method for simultaneous savings of all of those. This reveals a potentially powerful pattern to be researched in the future, in both technology and policy areas, creating benefits by linking several problems using synergy.

Publisher's Note Springer Nature remains neutral with regard to jurisdictional claims in published maps and institutional affiliations. 